\title{
Transpalatal Approaches to the Skull Base and Reconstruction: Indications, Technique, and Associated Morbidity
}

\author{
Nyall R. London Jr., MD, PhD ${ }^{1,2,3}$ jimmy Y. W. Chan, MD, MS, PhD ${ }^{4}$ Ricardo L. Carrau, MD, MBA ${ }^{1,5}$
}

${ }^{1}$ Department of Otolaryngology-Head and Neck Surgery, The Ohio State University, Columbus, Ohio

2 Department of Otolaryngology-Head and Neck Surgery, Johns Hopkins School of Medicine, Baltimore, Maryland

${ }^{3}$ Sinonasal and Skull Base Tumor Program, National Institute on Deafness and Other Communication Disorders, NIH, Bethesda, Maryland

${ }^{4}$ Division of Head and Neck Surgery, Department of Surgery, University of Hong Kong Medical Centre, Queen Mary Hospital, Hong Kong SAR, People's Republic of China

${ }^{5}$ Department of Neurological Surgery, The Ohio State University, Columbus, Ohio

Semin Plast Surg 2020;34:99-105.

\author{
Address for correspondence Ricardo L. Carrau, MD, Lynne Shepard \\ Jones Chair in Head and Neck Oncology, Departments of \\ Otolaryngology - Head and Neck Surgery and Neurological Surgery, \\ Wexner Medical Center, The Ohio State University, 320 W 10th \\ Avenue, Columbus, $\mathrm{OH} 43210$ \\ (e-mail: Ricardo.Carrau@osumc.edu; carraur!@gmail.com).
}

\begin{abstract}
Keywords

- transpalatal approach

- maxillary swing

- skull base surgery

Multiple anterior surgical approaches are available to obtain access to the nasopharynx, clivus, and craniocervical junction. These include the direct and transoral robotic surgery transpalatal, maxillary swing, and endoscopic endonasal approaches. In this article, we describe the indications for these techniques, surgical steps, and associated morbidities. This article is a PubMed literature review. A review of the literature was conducted to assess the techniques, surgical steps, and associated morbidities with transpalatal approaches to the skull base and nasopharynx. The transpalatal approach has been traditionally utilized to obtain surgical access to the nasopharynx, clivus, and craniocervical junction. Morbidity includes velopalatine insufficiency due to shortening of the soft palate from scar contraction or neuromuscular damage, thus leading to hypernasal speech and dysphagia. Middle ear effusion and oronasal or oronasopharyngeal palatal fistula are additional potential morbidities. The choice of surgical approach depends on a variety of factors including the disease location and extent, surgeon experience, and available resources.
\end{abstract}

Traditionally, transpalatal approaches have been utilized to obtain surgical access to the clivus and craniocervical junction. ${ }^{1,2}$ According to the area of the skull base that is the intended surgical target, the approach may be achieved via transoral transection of the soft and/or hard palate. Patients undergoing these approaches are at risk of developing velopalatine insufficiency (VPI) due to shortening of the soft palate from scar contraction or neuromuscular damage, associated with hypernasal speech and dysphagia, middle ear effusion, and oronasal or oronasopharyngeal palatal fistulas. ${ }^{3}$ Furthermore, in some instances the ensuing edema and potential postoperative bleeding associated with the approach mandates securing the airway with a tracheostomy. ${ }^{1}$ However, use of a direct transpalatal technique has significantly decreased with advances in endoscopic endonasal and transoral robotic techniques. An expanded endonasal approach (EEA) may be utilized to access the entire length of the clivus down to $\mathrm{C} 1$ and the odontoid process, and in some cases the superior aspect of $\mathrm{C} 2 .{ }^{4,5}$ An EEA may be combined with a transoral robotic approach to access disease
Issue Theme Special Topics in Palatal and Maxillary Reconstruction; Guest Editor: Sameep Kadakia, MD
Copyright $\odot 2020$ by Thieme Medical Publishers, Inc., 333 Seventh Avenue, New York, NY 10001, USA. Tel: +1(212) 760-0888.
DOI https://doi.org/ 10.1055/s-0040-1709432. ISSN 1535-2188. 
that may extend inferiorly. ${ }^{6,7}$ In contrast to a traditional transpalatal approach, an extended maxillectomy or maxillary swing approach is still required for the resection of extensive recurrent nasopharyngeal disease. ${ }^{8,9}$ Other alternative approaches, following a lateral to medial line-of-sight (e.g., transtemporal or subtemporal approaches), are also possible. In this article, we describe the indication for transpalatal techniques, including surgical steps and associated morbidities.

\section{Transpalatal Approach}

As aforementioned, transoral transpalatal approaches are commonly used to access lesions involving the nasopharynx, clivus, and craniocervical junction. As with any transoral procedure, access is largely dependent on the patient's ability to open their mouth. ${ }^{2}$ Thus, a patient with significant trismus may not be a candidate for this approach or may require a mandibular or maxillary osteotomies. ${ }^{1}$ Furthermore, transpalatal approaches are best avoided if a large dural resection or cerebrospinal fluid leak is anticipated, given the challenges with achieving a watertight dural seal and the subsequent risk of meningitis due to oral contamination. ${ }^{1,10}$

Advanced retractors allow exposing much of the craniocervical junction transorally without incising the palate. ${ }^{2}$ However, disease that extends superiorly to the upper clivus or nasopharynx may require transection of the soft and/or hard palate to access transorally. $1,2,11$

To perform the transpalatal approach, the patient is placed in a supine position. If cervical instability is present preoperatively, or possible as a result of the surgery, the head is stabilized and intraoperative nerve monitoring is used. ${ }^{1} \mathrm{~A}$ tracheostomy is commonly utilized to secure the airway during surgery and postoperatively. ${ }^{1}$ A mouth retractor (e.g., Dingman, $\mathrm{KH}$, or those manufactured by MedRobotic) aids to displace the tongue, buccal, and pharyngeal tissues to enhance the surgical access. The soft palate and mucosa overlying the hard palate are then infiltrated with $1 \%$ lidocaine with 1:100000 epinephrine. There is some variability in terms of where the soft palate incision is placed. ${ }^{1,2}$ Incisions through the mucoperiosteum of the hard palate are typically made laterally in an effort to reduce the risk of palatal fistula associated with a midline incision. The mucoperiosteum is then elevated off the palatine and premaxillary bones with care to preserve at least one of the paired greater palatine neurovascular bundles. ${ }^{1}$ The hard palate is then removed with either a drill or oscillating saw. ${ }^{1,2}$ After completion of resection of the skull base or craniocervical junction lesion, the soft palate as well as the mucosa overlying the hard palate is closed carefully with interrupted sutures in a multilayered fashion. ${ }^{1}$

In addition to a traditional transpalatal approach to the skull base, an approach to the parapharyngeal space via the soft palate has been described. ${ }^{12}$ This approach can be combined with an EEA or other approaches for resection of lesions with extent to the parapharyngeal space. To perform this approach, the lateral soft palate is infiltrated with $1 \%$ lidocaine with 1:100000 epinephrine. An incision is then made at the lateral soft palate (-Fig. 1A). Dissection then proceeds through the submucosal and muscular layers ( - Fig. 1B-D). This dissection continues until the parapharyngeal space is identified (-Fig. 1E). The lesion can then be removed (-Fig. 1F) and the muscular and mucosal layers can be closed in multilayer fashion.

The incorporation of transoral robotic surgery (TORS) in transpalatal approaches has been reported to aid in reduction in morbidity of standard transpalatal techniques. ${ }^{13}$ Furthermore, use of TORS affords three-dimensional visualization as well as instrumentation with a high range of flexible movement. ${ }^{6}$ A cadaveric feasibility study reported the use of TORS to access the inferior pharyngeal extent of nasopharyngeal disease after an endoscopic endonasal approach. This group reported use of this approach in two patients with nasopharyngeal disease with good results. ${ }^{6}$ A second recent report combined use of a transpalatal approach and a TORS system to resect skull base malignancy in a series of patients with chordoma with extension to the nasopharynx. ${ }^{13}$ To achieve access to the nasopharynx with the robotic system, the soft palate was either retracted with a suture or reflected with a mucoperiosteal incision. This group reported no intraoperative complications and limited postoperative morbidity and achieved a gross total resection in one case and a near total resection in the other two cases. ${ }^{13}$

\section{Maxillary Swing Approach}

An extended version of the transpalatal approach, known as the maxillary swing, may be useful to obtaining wider access to the skull base and nasopharynx. However, this approach has the disadvantage of requiring multiple facial and intraoral incisions and henceforth visible scarring, facial osteotomies, as well as the potential for malocclusion and trismus. ${ }^{14}$ This technique is still frequently utilized for nasopharyngectomy for large recurrent nasopharyngeal carcinoma due to the vast surgical access it provides. ${ }^{8,14,15}$ Primary nasopharyngeal carcinoma often responds well to current management of intensity-modulated radiation therapy with or without chemotherapy. Indeed, one study by the Hong Kong Nasopharyngeal Cancer Study Group of 3,328 patients noted local recurrence or persistent disease in $14 \%$ of patients. ${ }^{16}$ Re-irradiation is an option for recurrent cases but can be hampered by toxicities including mucosal necrosis or massive hemorrhage. ${ }^{17,18}$ Thus, endoscopic or open approaches such as the maxillary swing have been reported in cases where negative margins can be achieved. ${ }^{17}$ Another reported use of the maxillary swing technique has been for angiofibroma. $^{19}$

To perform this technique, the patient is placed in a supine position and tracheostomy is commonly performed. A Weber-Ferguson incision, or one of its many variants, is carried to extend between the central incisors (-Figs. 2-4). The intraoral incision then proceeds in a para-alveolar manner such that the palatal mucoperiosteal incision does not overlap with the intended midline palatal bony cut (-Figs. 5-6). This helps to reduce the risk of palatal fistula. ${ }^{15,20-22}$ Preplating is advocated prior to completing the maxillary osteotomies to hasten the reconstructive phase and prevent 


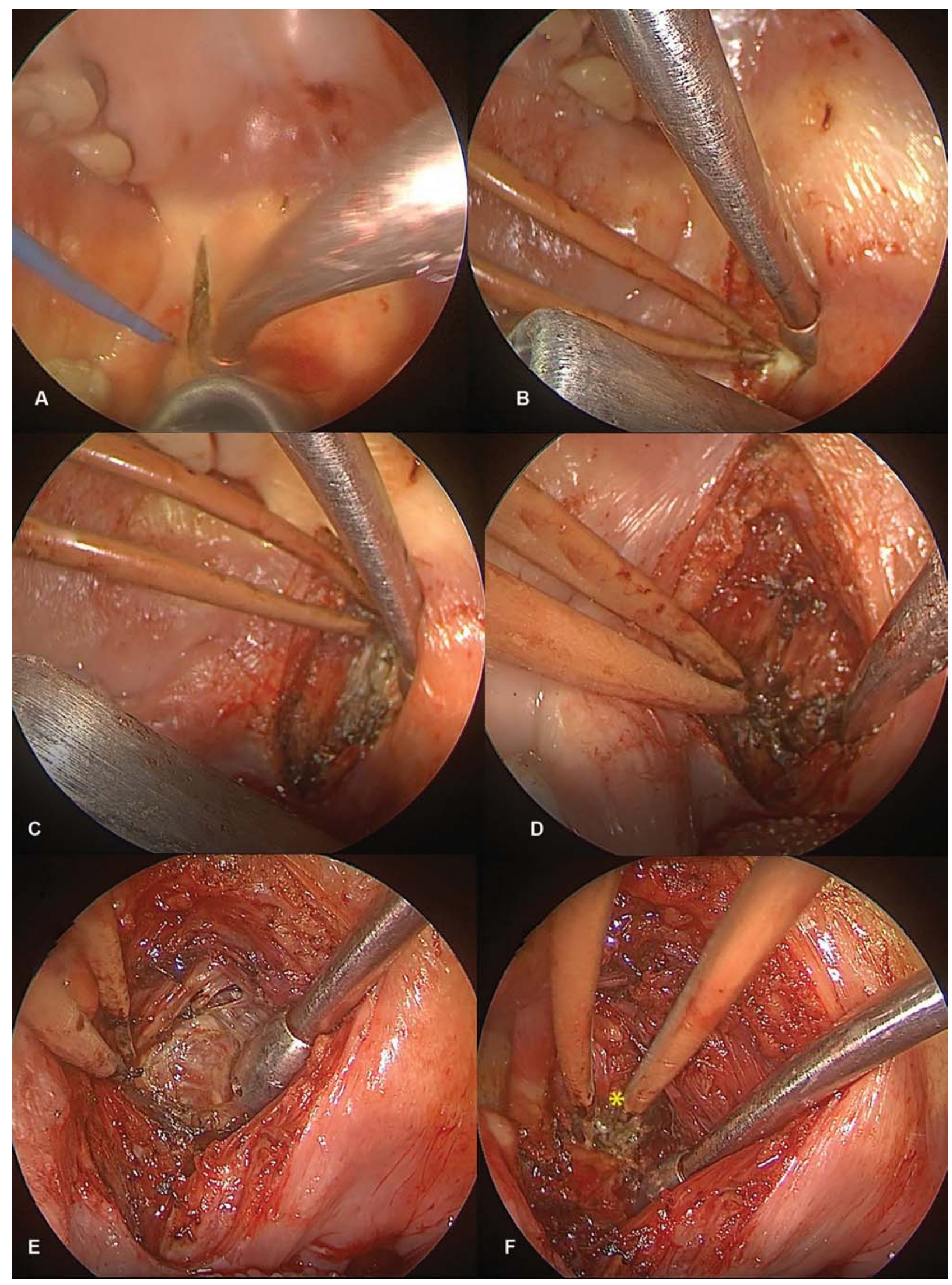

Fig. 1 An incision is made at the lateral soft palate (A). Dissection then proceeds through the submucosal and muscular layers (B-D). This dissection continues until the parapharyngeal space is identified $(\mathrm{E})$. The lesion can then be identified and removed $(\mathrm{F}$, asterisk indicates tumor). 


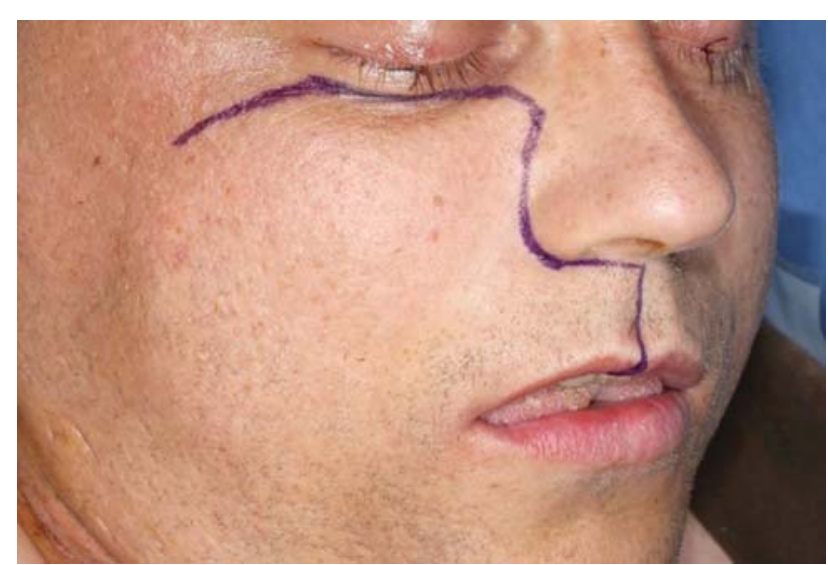

Fig. 2 Design of the Weber-Ferguson incision.

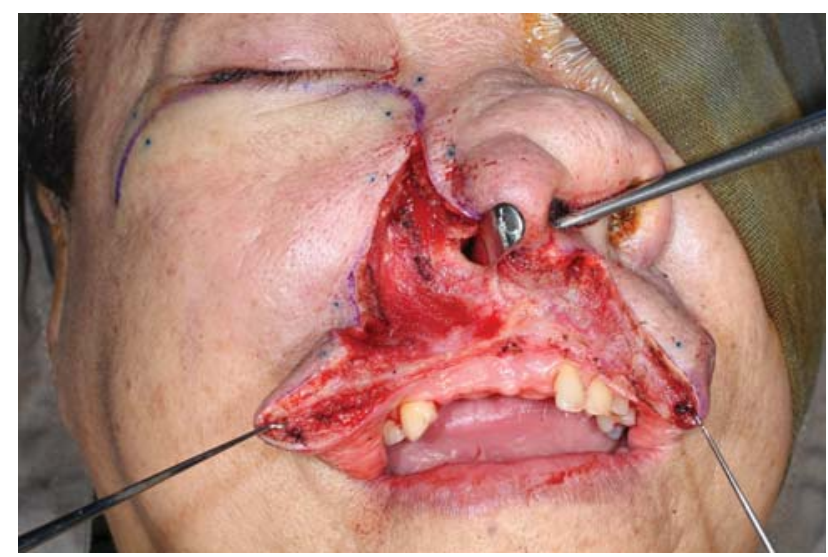

Fig. 3 Commencement of the Weber-Ferguson incision.

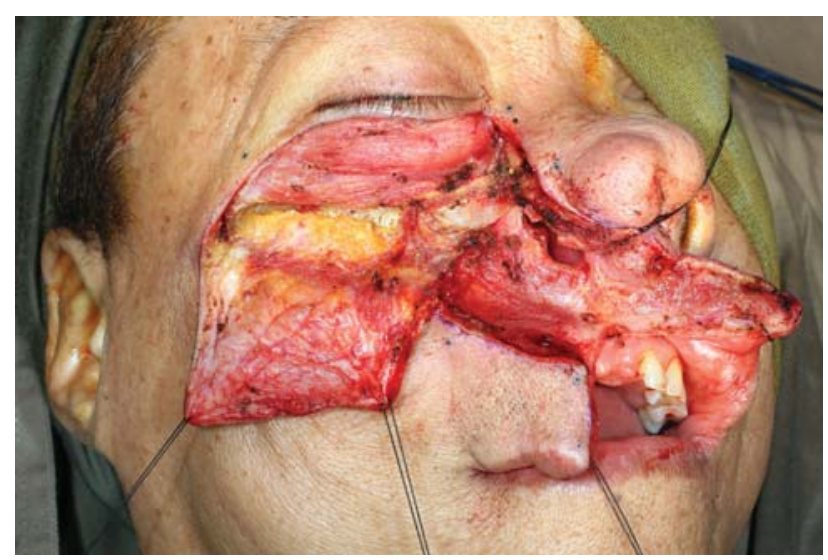

Fig. 4 Continuation of flap elevation.

postoperative malocclusion ( - Fig. 7 ) ${ }^{19}$ The planning of the osteotomies varies according to the preference of the surgical group and idiosyncrasies of the patient's anatomy or extent of the lesion but includes cuts through the frontal process of the maxilla, either the inferior orbital floor or the anterior maxillary wall, and laterally through either the zygoma or the zygomatic arch. To ultimately allow the maxilla to swing laterally, it needs to be released from the pterygoid plates

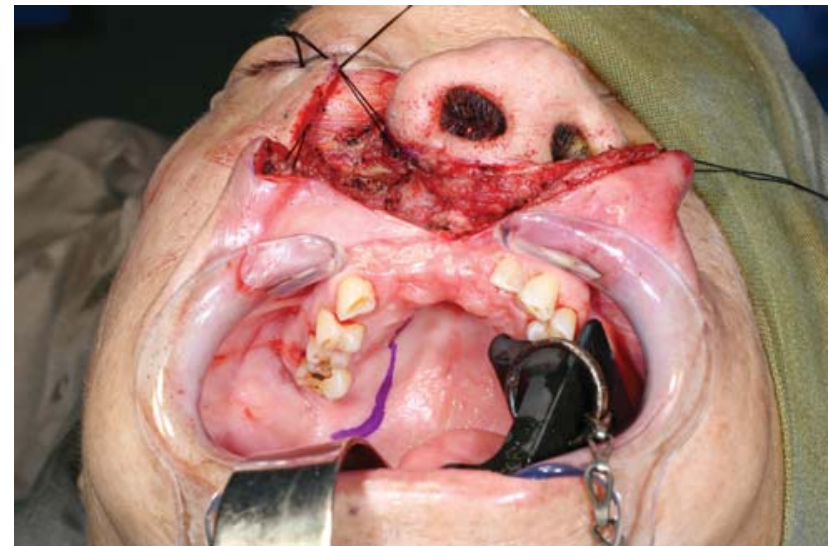

Fig. 5 Design of the intraoral incision.

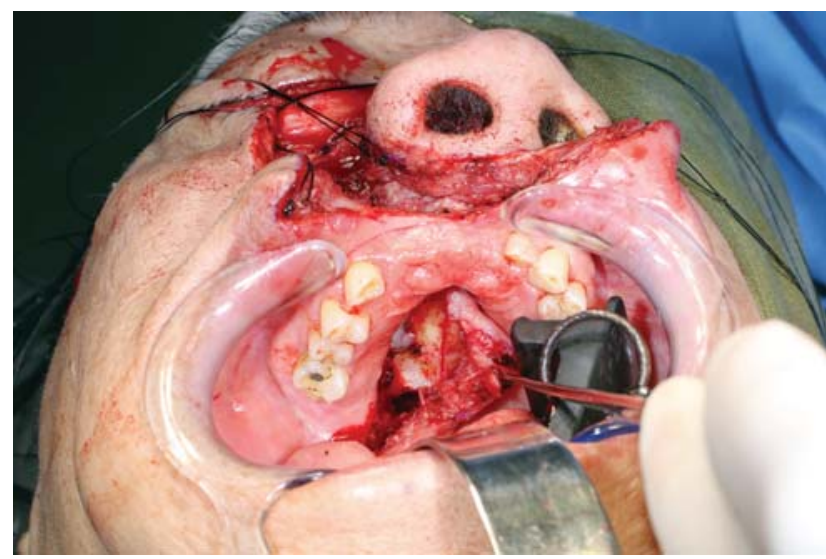

Fig. 6 Incision proceeds in a para-alveolar manner.

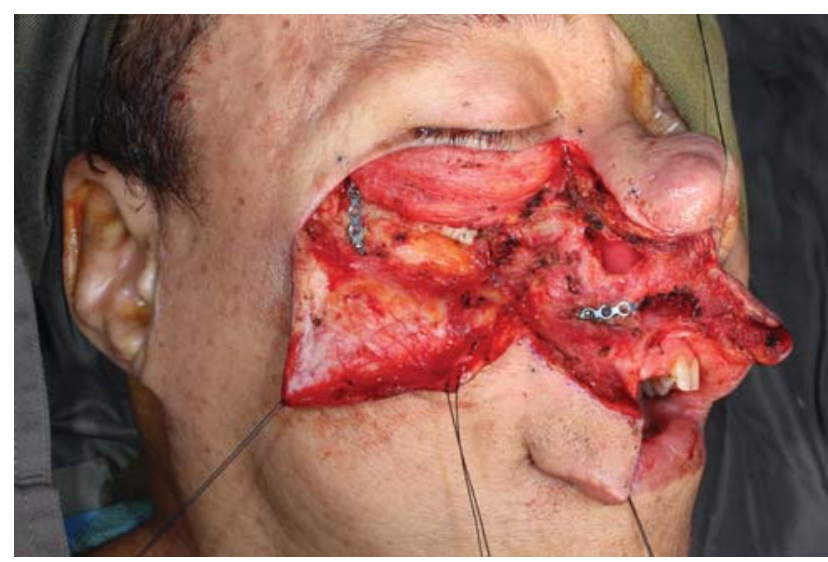

Fig. 7 Preplating is performed prior to osteotomies.

( - Fig. 8). Once the resection is completed, the maxilla is returned to its anatomical position and plated. The skin and intraoral incisions are then closed in a multilayered fashion (-Figs. 9-12). ${ }^{19}$

The morbidity profile after nasopharyngectomy using a maxillary swing approach has been reported in one study of 338 patients. ${ }^{14}$ In this study, the most frequently observed morbidity was middle ear effusion ( $40.8 \%$ ). However, middle 


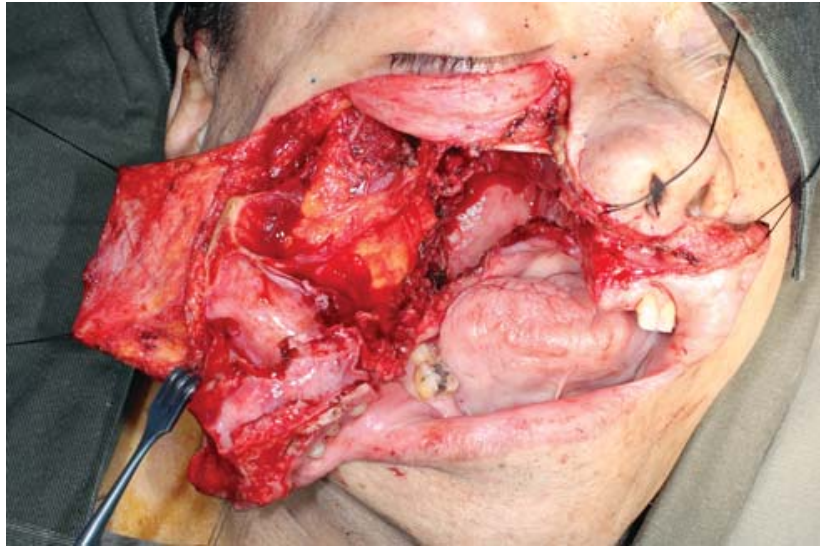

Fig. 8 The maxillary swing allows for wide access for open nasopharyngectomy.

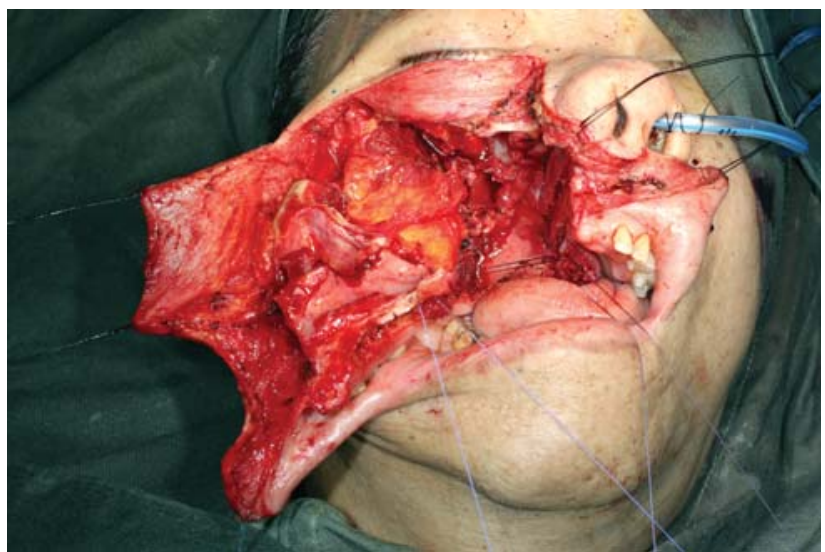

Fig. 9 The soft tissue is closed in a multilayer fashion.

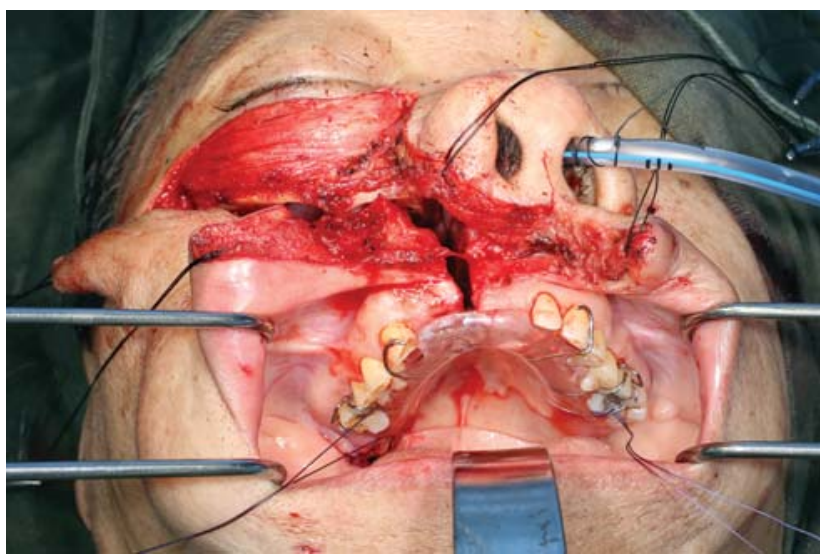

Fig. 10 The maxillary swing is reapproximated.

ear effusion is related to the resection of the Eustachian tube rather than the maxillary swing procedure itself. Trismus and palatal fistula were more frequent in their earlier study group, but in the more recent study group from 2002 to 2012 improved to 9.2 and $3.7 \%$, respectively. ${ }^{14}$ The incidence in nasal blockage increased in the more recent study group to $14.7 \%$, although it was likely related to the increased use of free tissue transfer for defect reconstruction. ${ }^{14}$ Another study of 62 patients that underwent maxillary swing noted

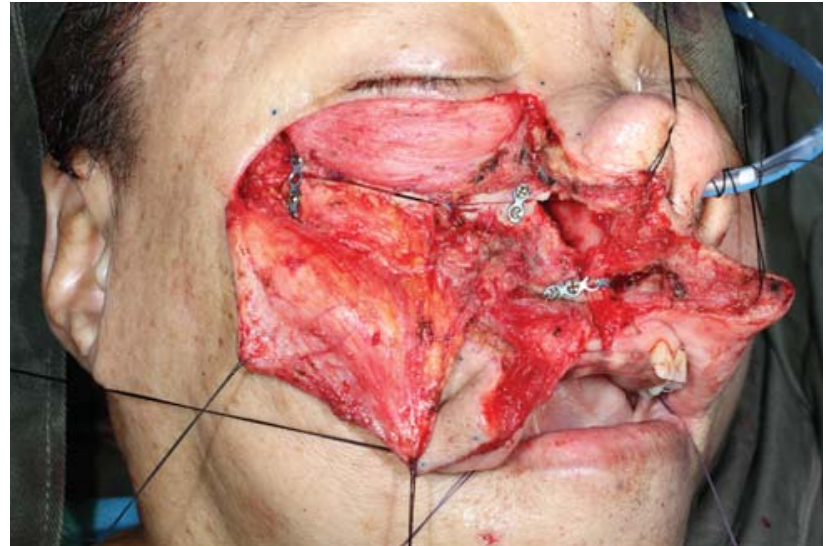

Fig. 11 Plating is performed for repair of osteotomies.

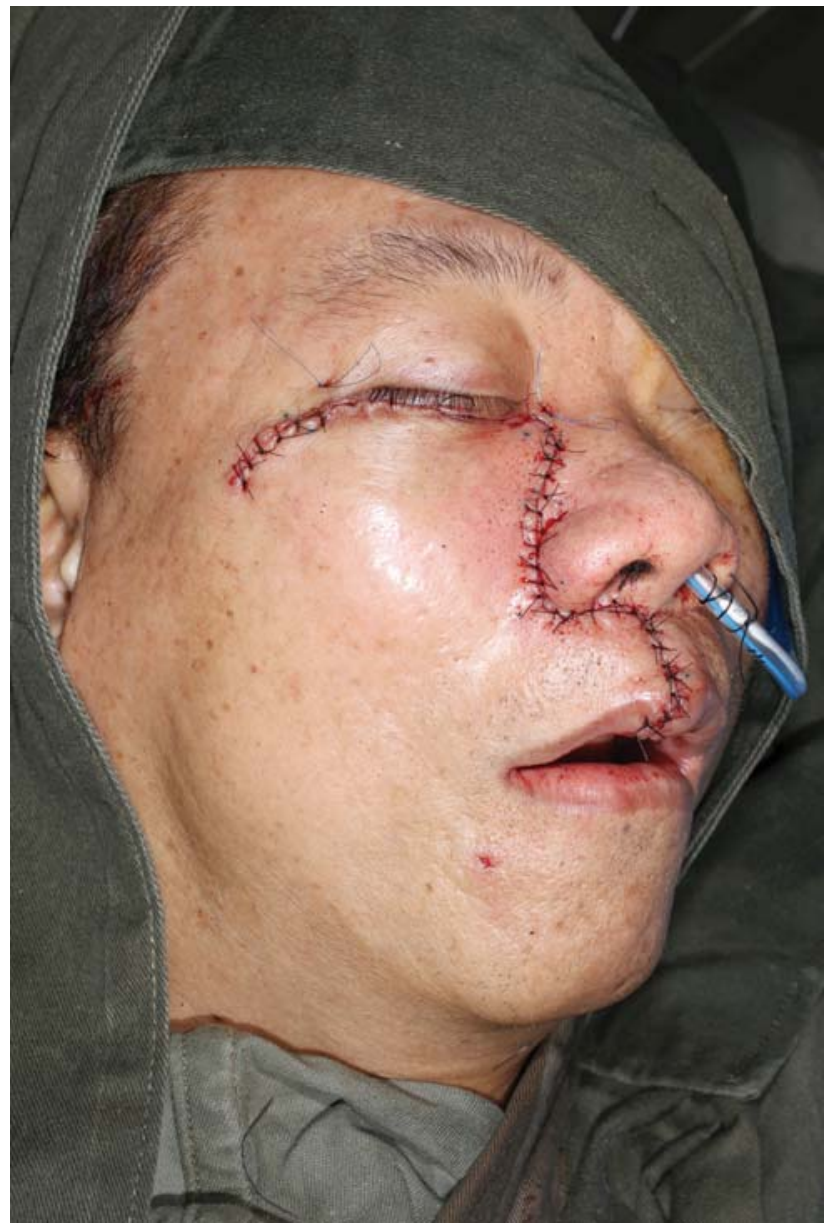

Fig. 12 The skin and soft tissue are closed in a multilayer fashion.

palatal fistula in one patient as well as mild nasal mucosa atrophy in one patient. ${ }^{19}$

\section{Endoscopic Endonasal Approach}

Rapid advances in endoscopic instrumentation and EEA techniques have significantly improved surgical access to the clivus and craniocervical junction. This allows for 
resection of lesions arising from or near the clivus and craniocervical junction such as chordoma, ecchordosis physaliphora, and meningiomas. ${ }^{23,24}$ Furthermore, EEA can be utilized in certain cases to resect recurrent nasopharyngeal carcinoma. ${ }^{25,26}$ Therefore, an endoscopic technique may be useful to reduce morbidities seen with transpalatal approaches.

Prior to performing an EEA for nasopharyngeal disease, a transcervical incision may be performed to identify and help secure the internal carotid artery. An endonasal approach is then utilized and a total ipsilateral sphenoethmoidectomy is performed. If the resection cavity can potentially be reconstructed with a nasoseptal flap rather than free tissue transfer, a contralateral nasoseptal flap is raised and preserved. This is followed by a posterior septectomy and reverse flap to cover exposed septal cartilage. A transpterygoid approach to the nasopharynx is then performed. ${ }^{27,28}$ An ipsilateral endoscopic medial maxillectomy is achieved with the removal of the posterior two-thirds of the inferior turbinate and the medial maxillary wall. Depending on the degree of lateral extension of the disease, a Denker's modification may need to be added to allow for adequate access. The ipsilateral sphenopalatine artery is cauterized and the posterior maxillary wall is removed. ${ }^{27,28}$ If possible, the descending palatine nerve is preserved to maintain innervation of the palate. The medial pterygoid plate is then drilled and removed to allow for resection of the cartilaginous Eustachian tube as well as the nasopharyngeal disease. After negative margins have been achieved, the contralateral nasoseptal flap can then be used to cover the resection bed. ${ }^{27,28}$ In cases where a nasoseptal flap may not be available, alternative regional flaps such as the temporoparietal fascia flap may also be incorporated to achieve adequate vascularized tissue coverage. If free tissue transfer is required, a tunneled retropharyngeal approach may be utilized to reconstruct defects of the clivus or nasopharynx. ${ }^{29}$

A recent anatomic study compared EEA versus maxillary swing on 10 cadaveric specimens. This study concluded that while the maxillary swing offered better access to the oropharynx and could be completed three times faster, the EEA provided precise definition of anatomic structures and a wide dissection range. ${ }^{30}$ The EEA has been shown to have a similar overall survival rate as an open approach. ${ }^{26} \mathrm{~A}$ recent study reported the surgical and oncological outcomes of endoscopic endonasal nasopharyngectomy for 55 patients with locally recurrent nasopharyngeal carcinoma. ${ }^{25}$ In this study of patients ranging from rT1 to rT4, negative margins were achieved in $93 \%$ of patients with a 1-year local diseasefree rate and survival rate of 93 and $98 \%$, respectively. ${ }^{25}$ Five patients had residual or recurrence at the surgical site and there was one case of intraoperative injury of the internal carotid artery. ${ }^{25}$ Another study pooled the analysis of 300 patients that underwent endoscopic resection of nasopharyngeal carcinoma and reported negative margins in $90.2 \%$ of patients and an overall survival of $82.9 \%{ }^{26}$ Thus, good surgical and oncologic results can be obtained with an endoscopic approach.

\section{Reconstruction}

Multiple techniques have been described to reconstruct palatal fistula and repair velopharyngeal insufficiency such as the sphincter pharyngoplasty, posterior pharyngeal wall, and posterior wall augmentation. ${ }^{31,32}$ One of the most common is the posterior pharyngeal flap, which may be raised from a superior versus an inferiorly based pedicle. Multiple techniques exist for harvesting the flap as well as multiple techniques for flap inset. ${ }^{33,34}$ The pharyngeal flap may be sutured to the palate to allow for repair and healing of the palatal fistula. ${ }^{35}$ In the event of velopharyngeal insufficiency, this technique allows for closure of the central velopharyngeal gap with lateral ports for breathing. ${ }^{35}$ The most common reason this technique fails is secondary to flap dehiscence. Furthermore, obstructive sleep apnea has been reported in 0 to $10 \%$ of patients as a result. ${ }^{35,36}$

An alternative technique that has been described as a potential option when traditional techniques are unavailable for pharyngeal reconstruction is the nasoseptal flap. ${ }^{37}$ The nasoseptal flap, which is harvested from the nasal septal mucosa with a posterior vascular pedicle, is the workhorse flap for reconstruction of skull base defects. A cadaveric study found that the nasoseptal flap could reach the upper oropharynx and could therefore serve as a potential reconstructive option for velopharyngeal insufficiency or soft palate reconstruction. ${ }^{37}$ Another study reported use of the nasoseptal flap to create a tube mucosal lined nasopharyngeal port followed by microvascular free flap reconstruction of the soft palate. ${ }^{38}$ Microvascular free flap reconstruction is also another option in pharyngeal defect reconstruction. This may be particularly useful when other techniques have failed or when a large tissue deficit exists. The free flap pedicle can be routed through several approaches depending on the location of the defect and whether an open or combine endoscopic technique is being utilized. ${ }^{29,39}$ Open pharyngeal free flap reconstruction provides a multitude of options for routing the pedicle and vascular anastomosis. When combined with an endoscopic technique, the flap can be tunneled through the retropharynx or alternatively the flap may be routed through the maxillary sinus with an anastomosis to the facial artery and vein. ${ }^{29,39}$

\section{Conclusion}

Multiple surgical approaches are available to obtain access to the nasopharynx, clivus, and craniocervical junction. These include the transpalatal, maxillary swing, and endoscopic endonasal approaches. The maxillary swing is an extension of the transpalatal approach and still commonly utilized for extensive nasopharyngectomy for recurrent nasopharyngeal carcinoma. The EEA has significantly changed utilization of the transpalatal approach and has become a viable option for experienced surgeons for nasopharyngectomy to resect lesions of the clivus and craniocervical junction.

Conflicts of Interest

The authors have no relevant conflicts of interest to disclose. 


\section{References}

1 Enepekides DJ, Donald PJ. Transoral approaches to the clivus and nasopharynx. Otolaryngol Clin North Am 2001;34(06): 1105-1121, ix ix.

2 Liu JK, Couldwell WT, Apfelbaum RI. Transoral approach and extended modifications for lesions of the ventral foramen magnum and craniovertebral junction. Skull Base 2008;18(03):151-166

3 Dubey SP, Molumi CP. Transpalatal approach with pedicled palatal osteo-muco-periosteal flap. ANZ J Surg 2012;82(06):439-442

4 Aldana PR, Naseri I, La Corte E. The naso-axial line: a new method of accurately predicting the inferior limit of the endoscopic endonasal approach to the craniovertebral junction. Neurosurgery 2012;71(2, Suppl Operative):ons308-ons314, discussion ons314

5 de Almeida JR, Zanation AM, Snyderman $\mathrm{CH}$, et al. Defining the nasopalatine line: the limit for endonasal surgery of the spine. Laryngoscope 2009;119(02):239-244

6 Carrau RL, Prevedello DM, de Lara D, Durmus K, Ozer E. Combined transoral robotic surgery and endoscopic endonasal approach for the resection of extensive malignancies of the skull base. Head Neck 2013;35(11):E351-E358

7 Chauvet D, Missistrano A, Hivelin M, Carpentier A, Cornu P, Hans S. Transoral robotic-assisted skull base surgery to approach the sella turcica: cadaveric study. Neurosurg Rev 2014;37(04):609-617

8 Chan JYW, Wong STS, Wei WI. Surgical salvage of recurrent T3 nasopharyngeal carcinoma: prognostic significance of clivus, maxillary, temporal and sphenoid bone invasion. Oral Oncol 2019;91:85-91

9 Muhanna N, Chan H, Qiu J, et al. Volumetric analysis of endoscopic and maxillary swing surgical approaches for nasopharyngectomy. J Neurol Surg B Skull Base 2018;79(05):466-474

10 Balasingam V, Anderson GJ, Gross ND, et al. Anatomical analysis of transoral surgical approaches to the clivus. J Neurosurg 2006;105 (02):301-308

11 Chan JY. Surgical salvage of recurrent nasopharyngeal carcinoma. Curr Oncol Rep 2015;17(03):433

12 Myatt HM, Remedios D. A transpalatal approach to the parapharyngeal space. J Laryngol Otol 1997;111(02):159-162

13 Henry LE, Haugen TW, Rassekh CH, Adappa ND, Weinstein GS, O'Malley BW Jr. A novel transpalatal-transoral robotic surgery approach to clival chordomas extending into the nasopharynx. Head Neck 2019;41(08):E133-E140

14 Chan JY, Tsang RK, Wei WI. Morbidities after maxillary swing nasopharyngectomy for recurrent nasopharyngeal carcinoma. Head Neck 2015;37(04):487-492

15 Wei WI, Lam KH, Sham JS. New approach to the nasopharynx: the maxillary swing approach. Head Neck 1991;13(03):200-207

$16 \mathrm{Au} \mathrm{KH}$, Ngan RKC, Ng AWY, et al. Treatment outcomes of nasopharyngeal carcinoma in modern era after intensity modulated radiotherapy (IMRT) in Hong Kong: a report of 3328 patients (HKNPCSG 1301 study). Oral Oncol 2018;77:16-21

17 Leong YH, Soon YY, Lee KM, Wong LC, Tham IWK, Ho FCH. Longterm outcomes after reirradiation in nasopharyngeal carcinoma with intensity-modulated radiotherapy: a meta-analysis. Head Neck 2018;40(03):622-631

18 Lam JW, Chan JY, Lui WM, Ho WK, Lee R, Tsang RK. Management of pseudoaneurysms of the internal carotid artery in postirradiated nasopharyngeal carcinoma patients. Laryngoscope 2014;124 (10):2292-2296

19 Kalra GS, Midya M, Bedi M. Access to the skull base - maxillary swing procedure - long term analysis. Ann Maxillofac Surg 2018;8(01):86-90

20 King WW, Ku PK, Mok CO, Teo PM. Nasopharyngectomy in the treatment of recurrent nasopharyngeal carcinoma: a twelve-year experience. Head Neck 2000;22(03):215-222
21 Hao SP, Tsang NM, Chang CN. Salvage surgery for recurrent nasopharyngeal carcinoma. Arch Otolaryngol Head Neck Surg 2002;128(01):63-67

$22 \mathrm{Ng} \mathrm{RW}$, Wei WI. Elimination of palatal fistula after the maxillary swing procedure. Head Neck 2005;27(07):608-612

23 Stippler M, Gardner PA, Snyderman CH, Carrau RL, Prevedello DM, Kassam AB. Endoscopic endonasal approach for clival chordomas. Neurosurgery 2009;64(02):268-277, discussion 277-278

24 Beer-Furlan A, Abi-Hachem R, Jamshidi AO, Carrau RL, Prevedello DM. Endoscopic trans-sphenoidal surgery for petroclival and clival meningiomas. J Neurosurg Sci 2016;60(04):495-502

25 Tang IP, Ngui LX, Ramachandran K, et al. A 4-year review of surgical and oncological outcomes of endoscopic endonasal transpterygoid nasopharyngectomy in salvaging locally recurrent nasopharyngeal carcinoma. Eur Arch Otorhinolaryngol 2019;276 (09):2475-2482

26 Vlantis AC, Lee DL, Wong EW, Chow SM, Ng SK, Chan JY. Endoscopic nasopharyngectomy in recurrent nasopharyngeal carcinoma: a case series, literature review, and pooled analysis. Int Forum Allergy Rhinol 2017;7(04):425-432

27 Al-Sheibani S, Zanation AM, Carrau RL, et al. Endoscopic endonasal transpterygoid nasopharyngectomy. Laryngoscope 2011; 121(10):2081-2089

28 Hosseini SM, McLaughlin N, Carrau RL, et al. Endoscopic transpterygoid nasopharyngectomy: correlation of surgical anatomy with multiplanar CT. Head Neck 2013;35(05):704-714

29 London NR Jr, Ishii M, Gallia G, Boahene KDO. Technique for reconstruction of large clival defects through an endoscopicassisted tunneled retropharyngeal approach. Int Forum Allergy Rhinol 2018;8(12):1454-1458

30 Roger V, Patron V, Moreau S, Kanagalingam J, Babin E, Hitier M. Extended endonasal approach versus maxillary swing approach to the parapharyngeal space. Head Neck 2018;40(06):1120-1130

31 Rauso R, Tartaro G, Califano L, Rugge L, Chirico F, Colella G. Pedicled palatal flap for surgical repair of oro-nasal fistula. J Biol Regul Homeost Agents 2018;32(06):1565-1567

32 Rochlin DH, Mittermiller PA, Sheckter CC, Menard RM. The pushback pharyngeal flap: an 18-year experience. Plast Reconstr Surg 2019;143(06):1246e-1254e

33 Ekin O, Calis M, Kulak Kayikci ME, Icen M, Gunaydin RO, Ozgur F. Modified superior-based pharyngeal flap is effective in treatment of velopharyngeal insufficiency regardless of the preoperative closure pattern. J Craniofac Surg 2017;28(02):413-417

34 Emara TA, Quriba AS. Posterior pharyngeal flap for velopharyngeal insufficiency patients: a new technique for flap inset. Laryngoscope 2012;122(02):260-265

35 El-Anwar MW, Elsheikh E, Askar S. Single-stage repair of palatal fistula and velopharyngeal incompetence by the new L flap. J Craniofac Surg 2018;29(01):e70-e73

36 Chegar BE, Shprintzen RJ, Curtis MS, Tatum SA. Pharyngeal flap and obstructive apnea: maximizing speech outcome while limiting complications. Arch Facial Plast Surg 2007;9(04):252-259

37 Rivera-Serrano CM, Lentz AK, Pinheiro-Neto C, Snyderman CH. Cadaveric study of the posterior pedicle nasoseptal flap: a novel flap for reconstruction of pharyngeal defects and velopharyngeal insufficiency. Plast Reconstr Surg 2013;132(05):1269-1275

38 Zenga J, Sharon JD, Gross J, Gantz J, Pipkorn P. Soft palate reconstruction after radionecrosis: combined anterolateral thigh adipofascial and nasoseptal flaps. Auris Nasus Larynx 2018;45 (04):875-879

39 Kang SY, Eskander A, Hachem RA, et al. Salvage skull base reconstruction in the endoscopic era: vastus lateralis free tissue transfer. Head Neck 2018;40(04):E45-E52 